\title{
Integrating methods for ecosystem service assessment: Experiences from real world situations
}

\author{
Rob Dunford ${ }^{\mathrm{a}, \mathrm{b}, *}$, Paula Harrison ${ }^{\mathrm{c}}$, Alison Smith ${ }^{\mathrm{a}}$, Jan Dick ${ }^{\mathrm{d}}$, David N. Barton ${ }^{\mathrm{e}}$, Berta Martin-Lopez ${ }^{\mathrm{f}}$, \\ Ezsther Kelemen ${ }^{\text {g,h }}$, Sander Jacobs ${ }^{i}$, Heli Saarikoski ${ }^{j}$, Francis Turkelboom ${ }^{i}$, Wim Verheyden ${ }^{i}$, \\ Jennifer Hauck ${ }^{\mathrm{k}, 1}$, Paula Antunes ${ }^{\mathrm{m}}$, Réka Aszalós ${ }^{\mathrm{n}}$, Ovidu Badea ${ }^{\circ}$, Francesc Baró ${ }^{\mathrm{p}, \mathrm{ag}}$, Pam Berry $^{\mathrm{a}}$,
} Laurence Carvalho $^{\mathrm{d}}$, Giulio Conte ${ }^{\text {af }}$, Bálint Czúcz ${ }^{\mathrm{n}, \mathrm{q}}$, Gemma Garcia Blanco ${ }^{\mathrm{r}}$, Dave Howard ${ }^{\mathrm{c}}$, Relu Giuca ${ }^{\mathrm{s}}$, Erik Gomez-Baggethun ${ }^{\mathrm{e}, \mathrm{p}, \mathrm{t}}$, Bruna Grizzetti ${ }^{\mathrm{u}}$, Zita Izakovicova ${ }^{\mathrm{v}}$, Leena Kopperoinen ${ }^{\mathrm{j}}$, Johannes Langemeyer $^{\mathrm{p}, \mathrm{ag}}$, Sandra Luque ${ }^{\mathrm{w}}$, David M. Lapola ${ }^{\mathrm{x}}$, Guillermo Martinez-Pastur ${ }^{\mathrm{y}}$, Raktima Mukhopadhyay $^{z}$, S.B. Roy ${ }^{z}$, Jari Niemelä ${ }^{\text {aa }}$, Lisa Norton ${ }^{c}$, John Ochieng ${ }^{\mathrm{ab}}$, David Odee ${ }^{\mathrm{ab}}$, Ignacio Palomo ${ }^{\mathrm{ac}}$, Patricia Pinho ${ }^{\mathrm{ad}}$, Joerg Priess ${ }^{\mathrm{k}}$, Graciella Rusch ${ }^{\mathrm{e}}$, Sanna-Riikka Saarela ${ }^{\mathrm{j}}$, Rui Santos ${ }^{\mathrm{m}}$, Jan Tjalling van der Wal ${ }^{\text {ae }}$, Angheluta Vadineanu ${ }^{\mathrm{s}}$, Ágnes Vári ${ }^{\mathrm{n}}$, Helen Woods ${ }^{\mathrm{d}}$, Vesa Yli-Pelkonen ${ }^{\text {aa }}$

${ }^{a}$ Environmental Change Institute, Dyson Perrins Building, South Parks Road, Oxford OX1 3QY, UK

${ }^{\mathrm{b}}$ Centre for Ecology \& Hydrology Maclean Building, Benson Lane, Crowmarsh Gifford, Wallingford, Oxfordshire OX10 8BB, UK

${ }^{c}$ Centre for Ecology and Hydrology, Lancaster Environment Centre, Library Avenue, Bailrigg, Lancaster LA1 4AP, UK

${ }^{\mathrm{d}}$ Centre for Ecology and Hydrology, Bush Estate, Penicuik, Midlothian EH26 0QB, UK

${ }^{\text {e }}$ Norwegian Institute for Nature Research (NINA), Gaustadalléen 21, 0349 Oslo, Norway

${ }^{\mathrm{f}}$ Leuphana University of Lüneburg, Faculty of Sustainability, Institute of Ethics and Transdisciplinary Sustainability Research, Scharnhorststraße 1, 21355 Lüneburg, Germany

${ }^{\mathrm{g}}$ Environmental Social Science Research Group (ESSRG Ltd.), Rómer Flóris u. 38., 1024 Budapest, Hungary

${ }^{\mathrm{h}}$ Department of Decision Sciences, Corvinus University of Budapest, Fövám tér 8., 1093 Budapest, Hungary

${ }^{i}$ Research Institute for Nature and Forest (INBO), Kliniekstraat 25, 1070 Brussels, Belgium

${ }^{\mathrm{j}}$ Finnish Environment Institute, P.O. Box 140, FI-00251 Helsinki, Finland

${ }^{\mathrm{k}}$ Helmholtz-Centre for Environmental Research - UFZ, Permoserstraße 15, 04318 Leipzig, Germany

${ }^{1}$ CoKnow Consulting - Coproducing Knowledge for Sustainability, Jesewitz, Germany

${ }^{\mathrm{m}}$ CENSE - Centre for Environmental and Sustainability Research, Faculdade de Ciências e Tecnologia, Universidade Nova de Lisboa, $2829-516$ Caparica, Portugal

${ }^{\mathrm{n}}$ Institute of Ecology and Botany, Centre for Ecological Research, Hungarian Academy of Sciences, Alkotmány u. 2-4, H-2163 Vácrátót, Hungary

${ }^{\circ}$ National Institute for Research and Development in Forestry "Marin Dracea", Eroilor Blvd 128, Voluntari, Romania

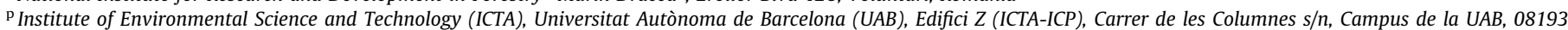
Cerdanyola del Vallès (Barcelona), Spain

${ }^{\mathrm{q}}$ European Topic Centre on Biological Diversity, Muséum national d'Histoire naturelle, 57 rue Cuvier, FR-75231 Paris, Paris Cedex 05, France

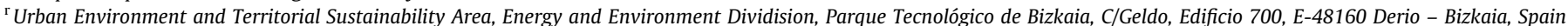

${ }^{\mathrm{s}}$ University of Bucharest - Research Center in Systems Ecology and Sustainability, Splaiul Independentei 91-95, 050095 Bucharest, Romania

${ }^{\mathrm{t}}$ Department of International Environment and Development Studies (Noragric), Norwegian University of Life Sciences (NMBU), P.O. Box 5003, N-1432 Ås, Norway

${ }^{\mathrm{u}}$ European Commission - Joint Research Centre (JRC), Via E. Fermi 2749, 21027 Ispra (VA), Italy

${ }^{\mathrm{v}}$ Institute of Landscape Ecology, Slovak Academy of Sciences, Štefánikova 3, 81499 Bratislava, Slovakia

${ }^{\mathrm{w}}$ IRSTEA, National Research Institute of Science and Technology for Environment and Agriculture, UMR TETIS, 500 rue JF Breton, Montpellier 34000, France

${ }^{x}$ UNESP - Universidade Estadual Paulista, Ecology Department - LabTerra, Av.24-A, 1515 CEP, 13506-900 Rio Claro, São Paulo, Brazil

${ }^{y}$ Centro Austral de Investigaciones Científicas (CADIC CONICET), Houssay 200, Ushuaia (9140) Tierra del Fuego, Argentina

${ }^{\mathrm{z}}$ IBRAD (Indian Institute of Bio Social Research and Development), VIP Road, Kestopur, Prafulla Kanan, Kolkata 700101, West Bengal, India

${ }^{\text {aa }}$ Department of Environmental Sciences, P.O. Box 65, FI-00014 University of Helsinki, Finland

${ }^{\mathrm{ab}}$ Kenya Forestry Research Institute (KEFRI), P.O.Box 20412-0200, Nairobi, Kenya

${ }^{\text {ac }}$ Basque Centre for Climate Change, Alameda de Urquijo 4, 48008 Bilbao, Spain

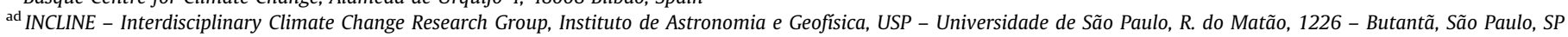
05508-090, Brazil

ae Wageningen University E' Research - Marine (WUR), P.O.Box 57, 1780 AB Den Helder, The Netherlands

af IRIDRA, Via La Marmora, 51 - 50121 Florence, Italy

${ }^{\mathrm{ag}}$ Hospital del Mar Medical Research Institute (IMIM), PRBB, Carrer Doctor Aiguader 88, 08003 Barcelona, Spain

\footnotetext{
* Corresponding author at: Environmental Change Institute, Dyson Perrins

Building, South Parks Road, Oxford OX1 3QY, UK.

E-mail address: Robert.Dunford@ouce.ox.ac.uk (R. Dunford).
} 


\section{A R T I C L E I N F O}

\section{Article history:}

Received 13 January 2017

Received in revised form 14 October 2017

Accepted 20 October 2017

Available online 15 November 2017

\begin{abstract}
A B S T R A C T
The Ecosystem Services (ES) concept highlights the varied contributions the environment provides to humans and there are a wide range of methods/tools available to assess ES. However, in real-world decision contexts a single tool is rarely sufficient and methods must be combined to meet practitioner needs. Here, results from the OpenNESS project are presented to illustrate the methods selected to meet the needs of 24 real-world case studies and better understand why and how methods are combined to meet practical needs. Results showed that within the cases methods were combined to: i) address a range of ES; ii) assess both supply and demand of ES; iii) assess a range of value types; iv) reach different stakeholder groups v) cover weaknesses in other methods used and vi) to meet specific decision context needs. Methods were linked in a variety of ways: i) as input-output chains of methods; ii) through learning; iii) through method development and iv) through comparison/triangulation of results. The paper synthesises these case study-based experiences to provide insight to others working in practical contexts as to where, and in what contexts, different methods can be combined and how this can add value to case study analyses.
\end{abstract}

(c) 2017 Published by Elsevier B.V.

\section{Introduction}

The popularisation of the Ecosystem Services (ES) concept has led to a significant uptake of ecosystem service based approaches in national and international policy frameworks (TEEB, 2010; Bateman et al., 2014; UN et al., 2014; IPBES, 2015; Maes et al., 2016). This, along with increased awareness of the interconnectedness of the natural environment and the widespread contributions of the natural world to human wellbeing, has put increasing pressure on practitioners in the land-use and environment sectors to assess and manage natural capital in a way that better reflects these holistic benefits.

This poses significant challenges. As the Ecosystem Service concept has become more widely recognised, so the number of tools/ methods (treated here as synonyms) available to assess ES has increased (Harrison et al., 2018; Bagstad et al., 2013). Individual ecosystem service tools, however, are often insufficient to meet the varied needs of land management challenges, and practitioners will therefore need to find the right combinations of tools to meet their needs - and to enable them to assess the broad range of values provided by nature (Jacobs et al., 2018). Whilst there are a number of studies that attempt to provide guidance on which tools to use under which circumstances (e.g. Vatn, 2009; Bagstad et al., 2013; Martinez-Harms et al., 2015; Ruckelshaus et al., 2015; Hirons et al., 2016; Grêt-Regamey et al., 2017), there has to date been no study that takes a bottom-up, example-based look at the range of tools required to address real-world case studies and the practical factors that drive the selection and combination of different methods.

The OpenNESS project (EU FP7; 2012-2017, www.opennessproject.eu) investigates the factors that influence the extent to which the Ecosystem Service concept can be put into practice in 24 real-world case studies, predominantly in Europe, but also in India, Kenya, Argentina and Brazil (see Table SM1 and Wijna et al., 2016 for further information). These case studies provide a test bed for assessing the utility of ecosystem service tools in practice, and the way in which different tools can be combined to address real-life problems. Within this paper we address three research questions:

1) What methods were combined within the case studies?

2) What factors drove the use of combinations of methods?

3) How were different methods combined within the case studies, and did this add value?
We aim to provide grounded insights and examples to assist others embarking on ecosystem service assessments where priorities are driven by practical end-user needs.

\section{Methodological approach}

The OpenNESS case-studies address a range of ecosystem management/planning challenges that were selected by practitioners (Table SM1). In each case study a research team, funded by the project, worked alongside a team of local stakeholders who are involved with the management of and/or have some interest and/or dependency on the case study's central issue. Case study teams were able to choose one or more tools to meet their needs, with training being provided. This paper is based on the research teams' explanations of the factors that influenced their selection and combination of tools to meet the stakeholders' needs.

The methods available for selection by the case study teams are listed in full in Table SM2. There are many ways to group methods but within this paper we group them into seven classes according to the type of ES values assessed: biophysical, socio-cultural or monetary (Gómez-Baggethun et al., 2016), as shown in Fig. 1. The classification also reflects the level of stakeholder participation, the level of biophysical realism reflected within the model (following Lavorel et al., 2017) and which parts of the ES cascade the method focusses on (biophysical structures and functions, ecosystem services or benefit and values to humans; Haines Young and Potschin, 2010). The main classes of model are summarised below.

Biophysical models: These process-based models assess biophysical value using a higher level of biophysical realism than approaches based on land-use proxies. They are based on detailed quantitative understanding of biophysical relationships within the environment and tend to focus on the structure/function part of the ES cascade. It is rare, but possible, to include stakeholder participation within the modelling.

Integrated mapping-modelling approaches: These combine spatial approaches with an element of bio-physical modelling to extrapolate from spatial datasets to ecosystem services. They are often designed specifically to address ecosystem services and include established methods such as InVEST and ESTIMAP (Zulian et al., 2014).

Land-use scoring approaches: This includes approaches based primarily on mapped data that produce ES outputs by applying some kind of expert-scoring. Referred to here as the "matrix 


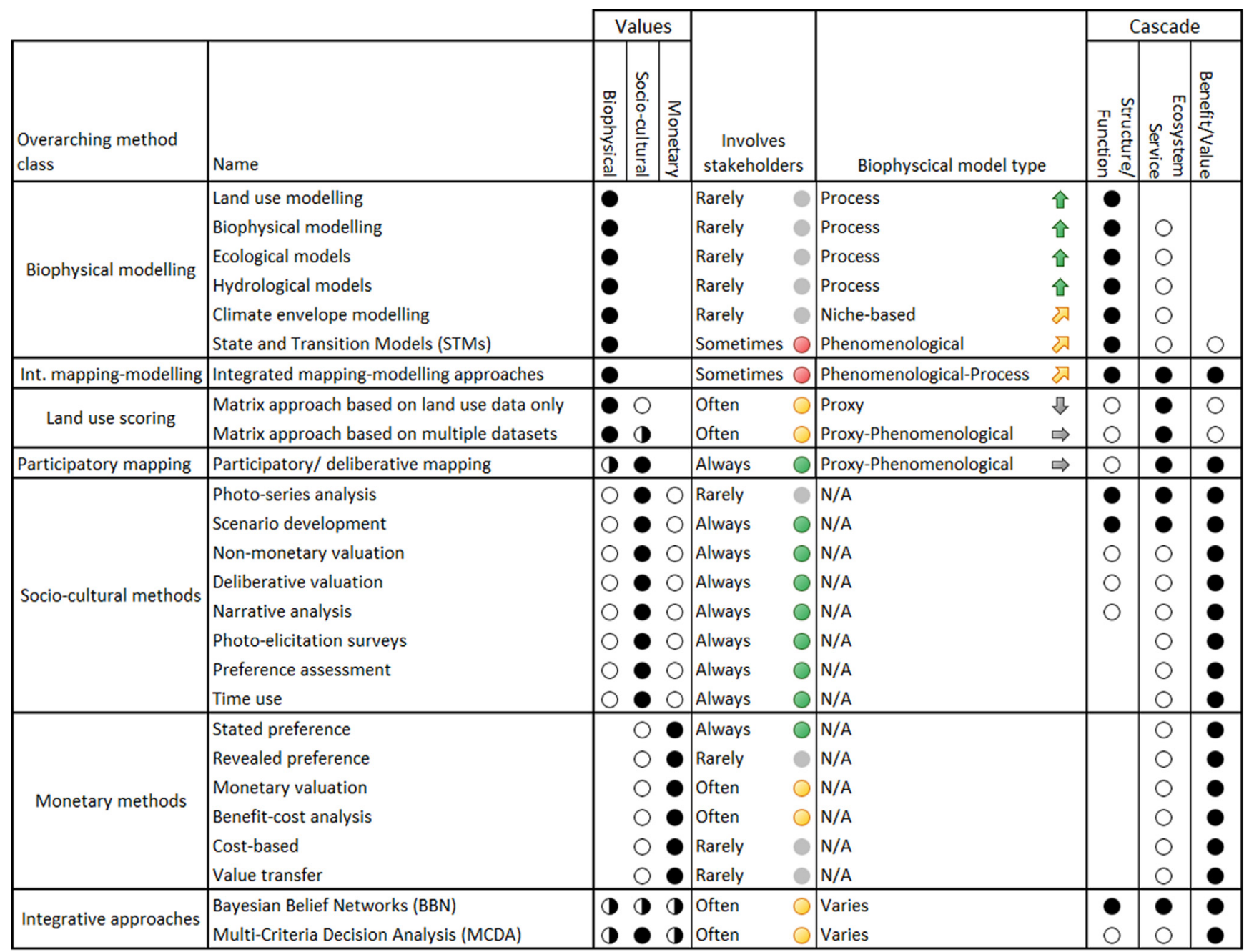

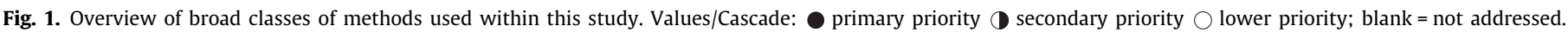

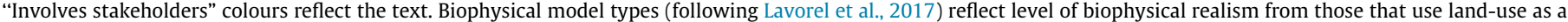

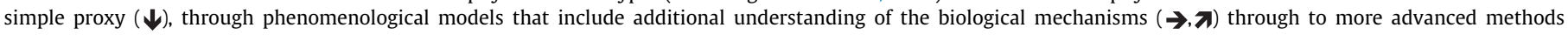
including niche- and trait-based approaches and process models of the biophysical system ( $\boldsymbol{\uparrow})$.

approach" these methods include both the simple matrix (Burkhard et al., 2012) which uses only land-use as a proxy for ecosystem service provision, and more advanced versions such as GreenFRAME (Kopperoinen et al., 2014) which build in more biophysical understanding by using additional datasets.

Participatory mapping: These approaches use mapping to capture both spatial and socio-cultural data directly from stakeholders. The priority is on capturing socio-cultural values, but biophysical value (extent and location of biophysical units) are often captured also. It always involves stakeholders and focuses on both ecosystem services and values. Participatory GIS (PGIS) is a commonly used participatory mapping example.

Socio-cultural methods: A wide range of methods that prioritise socio-cultural values for ecosystem services, including nonmonetary alternatives to common monetary approaches (e.g. time use, preference assessment) and deliberative and narrative approaches (such as interviews and focus groups). One approach commonly used within OpenNESS is the "photoseries" methodology which involves the assessment of cultural ecosystem services revealed in photos uploaded on social media (e.g. Flickr; Martínez Pastur et al., 2016; Tenerelli et al., 2016).

Monetary methods: Approaches that carry out monetary valuation of ecosystem services through a range of means (such as value transfer, revealed or stated preference). Some of these methods include stakeholder participation and all focus on the value/benefit side of the cascade.

Integrative approaches: these methods are designed to synthesise data and are capable of integrating data that cover a wide range of different types of values. Within this paper this class refers to Bayesian Belief Networks (BBNs) and Multi-Criteria Decision Analysis (MCDA). However, it should be noted that a) these approaches do not have to be used to integrate across value types (e.g. BBNs can be used for purely biophysical data) and b) other methods can also play a role integrating across value types (e.g. deliberative workshops, stakeholder meetings or project reports).

Data on tool use was collected through a series of questionnaires and workshops with the 24 case study research teams (Fig. 2). Initial surveys (Q1) encouraged research teams to express in their own words the reasons for the selection of individual tools. This data was interpreted and coded into themes that reflected the major factors taken into consideration when methods were selected (Table SM3). These factors, referred to as "considerations" within this paper, covered a broad range of issues under six main themes:

1) the types of ecosystem service that were the focus of the case study; 
October 2013 (WS1) Initial discussions with case study research teams about which methods they might use.

November 2014 (WS2) Training workshop at which methods were showcased and practical support with them was offered

Jan 2015 Q1: Initial questionnaire to identify which methods are being used, for what purposes and why the methods had been selected.

April $\mathbf{2 0 1 5}$ (WS3) Method combination workshop to explore the ways that different methods were used in combination. Experiences across case studies were shared.

October 2015 (WS4) Methodology mind-mapping

workshop: mind maps were used to describe the process of method selection within the cases

September 2016 Q2: Method use questionnaire to identify

and assess the considerations that had led to method

selection to date within the cases.

Fig. 2. Timeline providing an overview of workshops (WS1-4) and questionnaires (Q1\&2) focussed on method combinations.

2 ) the management or policy context of their study: e.g. were they interested in exploring ideas, providing information, making decisions or designing policy instruments; for more information see Barton et al., (2018);

3) a range of pragmatic constraints that might have influenced their choice of methods: such as budget, time and expertise;

4) considerations related to the research process, such as whether the technique was novel, transferable and produced scientifically robust results;

5) particular methodological considerations, such as a method's ability to involve stakeholders, provide spatially explicit outputs or address uncertainty;

6) and factors related to the stakeholder-driven nature of the OpenNESS research, such as whether the method selection was driven by the end-users themselves.

A further survey (Q2) was circulated after completion of the case studies, in which the research teams were asked to score the extent to which each of the considerations influenced their decision to use each method ( $0=$ not at all; 1 = to some extent; 2 = definitely). They were also asked to assess, in free text: i) their reasons for combining methods; ii) whether the combination of methods they used met their aims; iii) any problems and challenges resulting from combining methods and iv) their views on the impact of method combination on the scientific robustness of the results (Table SM4).

In addition to survey data, workshops were used to ascertain how the case studies were using methods to meet their specific goals (WS1-4) and to understand how methods were being combined (WS 3-4). The final workshop (WS4) produced participatory mind maps detailing the methods used, the ways in which meth- ods are combined and the considerations that influenced method selection and combination.

The questionnaires and mind maps were thematically analysed across all case studies to identify common factors influencing selection of individual methods and the way in which methods were combined. Where necessary, ad hoc interviews with the case study research teams were used to fill in additional details and clarify uncertainties.

\section{Results}

\subsection{What methods were combined within the OpenNESS case studies?}

The 24 case studies cover a wide range of biophysical contexts (e.g. forests, cities, mixed rural areas, rivers and coasts) and varied land management challenges and policy contexts (see SM1 and Dick et al., (2018), for details). As such, a wide range of methods were selected and combined within the case studies (Fig. 3).

The number of methods combined varies widely: most case studies (75\%) combined at least four methods and $42 \%$ combined six or more, with one (Oslo) combining 15 . Socio-cultural and participatory mapping methods were the most commonly used method classes (used in $83 \%$ and $67 \%$ of studies respectively), with all but two studies using at least one of these methods. Integrated mapping-modelling approaches and biophysical modelling were used less often (46\% and 38\% respectively) and land-use scoring approaches were only used in $25 \%$ of cases, but all but five cases used at least one of these methods. Monetary methods were only used in a third of case studies. Just under half of case studies used either MCDA or BBNs as an integrative method, with two combining both of these methods.

\subsection{What factors drive the need for method combination?}

Analysis of the questionnaires, mind-maps and supplementary interviews (Table SM4) revealed six overarching factors that drive the need to combine different methods within a case study:

a) a need to assess a range of different ES beyond those possible with a single method;

b) a need to assess different elements of the ES cascade, i.e. to look at both supply and demand, or at different elements of ecosystem structures, functions, services, benefits or values;

c) a need to assess different aspects of value (biophysical, socio-cultural, monetary) within a case study;

d) a need to engage with different types of stakeholder;

e) a need to address methodological concerns relating to the use of a single method (e.g. to increase robustness, for validation);

f) selecting methods to address different stages of the research/case study's development.

The following Sections 3.2.1-3.2.6 focus on each of these factors in turn, demonstrating the approaches taken within the OpenNESS case studies with reference to Figs. 4 and 5. Fig. 4 lists each case study against the capabilities of the models they chose to use (from Fig. 1). Fig. 5 combines results from all case studies, grouping the method selection considerations according to how they address the six overarching factors for combining methods (a to $f$ above).

\subsubsection{Selecting methods to address a range of different ES within a} case study

Why is this important?. One of the primary advantages of the ecosystem service approach is its holistic approach to the natural environment (considering provisioning, regulating and cultural 


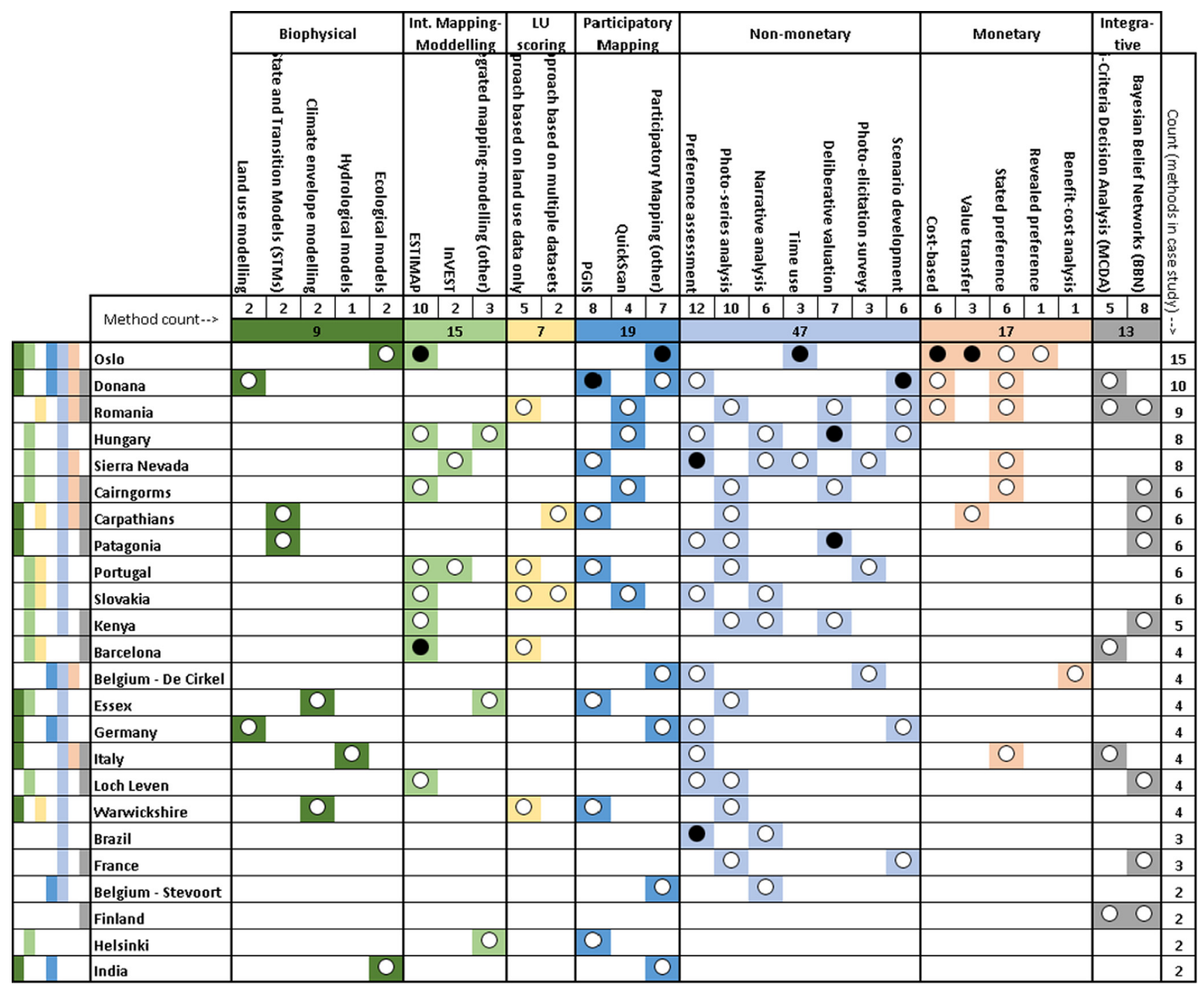

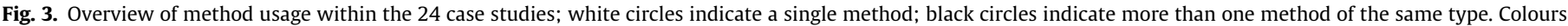
reflect overarching method classes; the coloured bars on the left indicate presence or absence of at least one method of each class.

services). As such, having methods that can provide insights across the range of ecosystem services is a high priority to many practitioners: Fig. 4a shows that 20 of the 24 OpenNESS cases cover the full range of ecosystem service types with at least one method in each type.

How was it addressed in the OpenNESS case studies?. For most of the case studies at least one method was selected because it was capable of addressing provisioning, regulating and cultural ecosystem services together. Other methods could then be combined with these approaches to focus on particular ecosystem services of interest such as cultural ecosystem services (Essex, Germany, Warwickshire); pollination services (Portugal, Barcelona) or soil erosion (Barcelona), or to address other priorities of the case study.

The broad range of methods used within OpenNESS to assess a cross-section of ecosystem services is shown in Fig. 5a. Land-use scoring and participatory/deliberative mapping approaches were the main two method classes used for this purpose with "addressing the full range of ES" being selected as a consideration $57 \%$ and $55 \%$ respectively. The individual methods used most often were the three individual participatory mapping approaches (participatory mapping (5), QUICKScan (3) and PGIS (3)); three socio-cultural methods (preference assessment (5), narrative analysis (4) and scenario development (3)) and the integrative method MCDA (3).
However, in the Hungarian and Kenyan case studies methods were combined that each individually addressed different ecosystem service types. As an example, the Hungarian case assessed cultural ecosystem services using narrative approaches and preference assessment; provisioning and supporting services through participatory mapping, and regulating services using integrated mapping and modelling.

The fact that socio-cultural, integrative and land-use scoring approaches can all address a range of ES highlights that there are a range of different ways the suite of ES can be understood, from maps of quantified ES values through to stories of ecosystem service provision from in depth interviews with stakeholders or textual analysis.

\subsubsection{Selecting methods to address different elements of the ES cascade}

Why is this important? In many cases it is important not only to know the state of the ecosystem in terms of its structure and the functions it performs (e.g. how much forest there is and how much it reduces flows to rivers) but to understand the services it supplies to people (reducing flooding), the demand for the service (number of people in the flood plain) and its value (e.g. avoided flood 


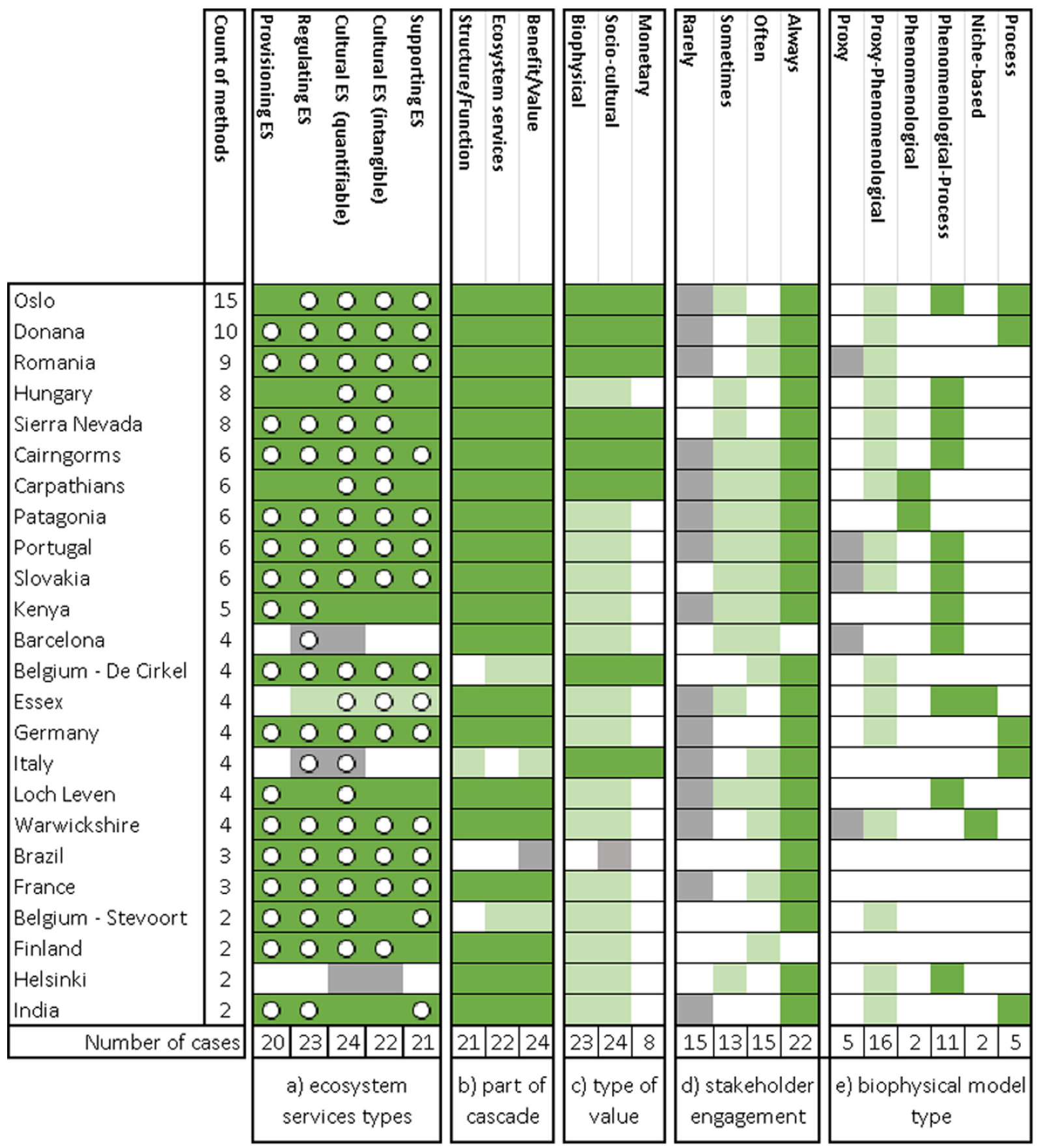

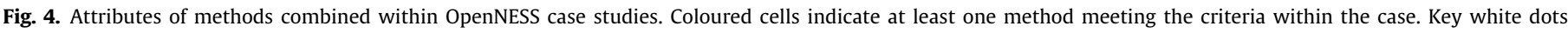
indicate more than one method addressing that type (ES types only). Shades of green used to illustrate increasing levels of each attribute (a-f).

damage). As such, in many practical contexts it is important to have methods that can evaluate both ES supply and demand.

How was it addressed in the OpenNESS case studies?. Twenty of the 24 case studies contained methods capable of addressing ES supply and/or demand. Of these, all but three contained one or more individual methods which they selected due to their ability to address both supply and demand. As above, they then combined these with other methods which addressed other priorities within the case.

Integrated mapping-modelling approaches were most often selected for their ability to address supply and demand (in 53\% of cases; Fig. 5b) with other methods only selected for this reason in $<30 \%$ of cases. The most commonly used individual methods were ESTIMAP and photoseries analysis (5 times each) followed by BBNs, participatory GIS and scenario development (3 times each). In the cases that did not highlight supply and demand as method selection considerations (Finland, Doñana and Romania), methods were used that could be applied to either supply or demand but these were focussed primarily on supply. In Doñana two methods capable of addressing either supply or demand were used separately to get an overview: MCDA was used to address supply whilst participatory/deliberative mapping was used to assess demand.

The methods used reflect very different potential understandings of supply and demand within a case. ESTIMAP, for example, can be used to map high biodiversity areas (ES supply) but also to model how accessible it is from nearby settlements (a proxy 


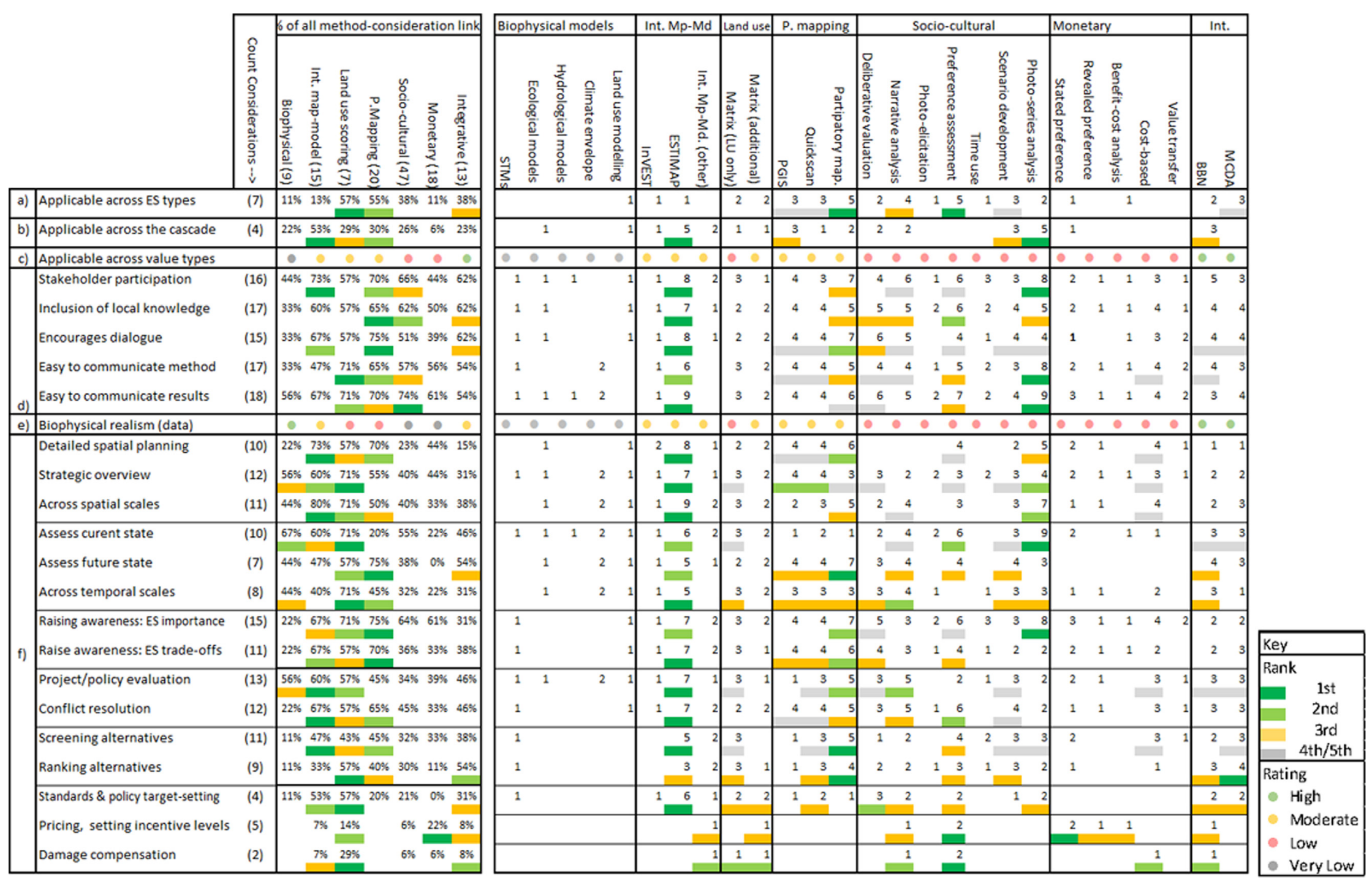

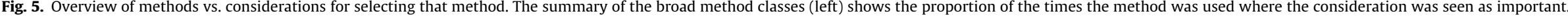
The summaries of the individual methods (right) show counts of the times the consideration was considered when selecting the method. 
for ES demand). In photoseries analysis the photographs taken not only show the existence of the structure providing the service (e.g. an attractive forest) but also provide evidence that the service is being used (e.g. a human is enjoying the view enough to photograph it). For this reason cases often combine approaches to get more rounded views of the same issue (e.g. Cairngorms, Loch Leven: Tables SM1 and SM4).

\subsubsection{Selecting methods to assess different aspects of value for ES}

Why is this important?. There are many ways of classifying value (see IPBES, 2015) but here we focus on the three traditional classes of value: biophysical, socio-cultural and monetary (GómezBaggethun et al., 2016). The differences in how a problem can be understood through monetary units (e.g. price/ha timber), biophysical units $\left(\mathrm{MtCO}_{2} \mathrm{e}\right.$ of carbon storage) and socio-cultural values ("I love forests") exemplify the challenge of assessing the value of ecosystem services to human wellbeing. There was great interest within many of the case studies in ensuring that a broad range of values were reflected beyond the monetary values often prioritised in decision making, particularly socio-cultural and biophysical values. Fig. 4c shows that all but one case study selected methods that assess multiple types of value, and that 23 cases assessed both biophysical and socio-cultural values. Monetary valuation was applied in only eight cases.

How was it addressed in the OpenNESS case studies?. Values were assessed by combining different methods from across the overarching method classes illustrated in Fig. 1. Eight cases combined at least one monetary method with a socio-cultural method and either a biophysical, integrated mapping-modelling or land-use scoring method to assess biophysical values. Of the other cases, all but four combined at least one of the three method classes for assessing biophysical data and at least one socio-cultural method. Furthermore, 19 of the 24 cases (Fig. 3) used participatory/ deliberative mapping approaches which facilitate the capture of sociocultural views and values (through their participatory nature) as well as being capable of capturing biophysical data related to the location and quality of ES-providing structures. Integrative approaches (BBNs and MCDA) were used in 13 cases as a means of integrated valuation: providing a mechanism to draw together, weight and make decisions using values from different sources in different units.

\subsubsection{Selecting methods to reach different stakeholder groups}

Why is this important?. In case studies where the ecosystem service concept is being put into practical use there will be a range of stakeholders with different levels of interest in, engagement with, agency over and dependency on the issue of concern. These stakeholders will draw their understanding of their environment and the specific case study problem from a range of different knowledge bases, both from scientific studies and from their own local knowledge and lived experience. For the ecosystem services concept to contribute to their understanding of the issue at hand, there is a need for methods that facilitate discussion and allow stakeholders with different types and levels of knowledge to engage with the assessment.

Within the OpenNESS cases there are a range of different examples of why this was necessary. In India, for example, there was a need to build understanding between local communities living in degrading forests and forest authorities managing the forests. In Brazil and Kenya there was a need to find methods to build understanding by people with different levels of formal education and familiarity with ecosystem services language and terminology. In Hungary and Finland, there was a need to build understanding between stakeholders, researchers with natural and social science backgrounds and practitioners with lived experience of the issues under study. In Patagonia, different methods were needed to communicate with land managers, researchers and local people.

How was it addressed in the OpenNESS case studies?. Most (22) of the case studies used methods that always include stakeholders actively within the process. The research teams identified five different aspects of stakeholder engagement that were considerations when selecting methods. These were: i) the method involved stakeholder participation; ii) the method facilitated the inclusion of local knowledge; iii) the method encouraged dialogue between stakeholders; iv) the method itself was easy to communicate and v) the results of the method were easy to communicate.

Facilitating stakeholder participation was scored as a major consideration across all method classes but particularly within integrated mapping and modelling (73\%), participatory mapping (70\%) and socio-cultural approaches (66\%) (Fig. 5d). Different method classes were selected to address different stakeholderrelated aspects. Encouraging dialogue was a major consideration in the selection of participatory mapping approaches (in $75 \%$ of cases), and also for integrated mapping-modelling (67\%) and integrative approaches (62\%). However, land-use scoring approaches ranked highly for ease of explanation of method and results $(71 \%$ for both). Inclusion of local knowledge was a consideration in $50-65 \%$ of cases for all method classes except for biophysical modelling (33\%).

The individual method most commonly selected for stakeholder engagement considerations was ESTIMAP mapping-modelling (Zulian et al., 2014) which was modified within OpenNESS to facilitate greater stakeholder engagement. Photoseries, participatory mapping, preference assessment and deliberative and narrative approaches were also ranked highly, particularly with respect to the inclusion of local knowledge. Of these, photoseries ranked highly for ease of communication whilst participatory GIS and deliberative valuation (e.g. workshops) were commonly selected to stimulate dialogue.

\subsubsection{Combining methods to address concerns with using a single} method

Why is this important?. In a number of cases methods were combined as a response to other methods applied within the case (either before or after the method in question). This could be:

i) to provide inputs to (or receive inputs from) another method;

ii) to further develop the existing approach e.g. to improve its accuracy, or integrate aspects of other approaches;

iii) to triangulate findings between different methods to increase confidence or assess uncertainty in the results;

iv) to address another priority not addressed by the previously selected approach;

v) to follow up a subject of interest highlighted by the results of the previous approach;

vi) to respond to changes in the research/decision context or the stakeholder priorities;

vii) to attempt the approach at a different location, or at a different spatial scale or resolution; or

viii) to address perceived weaknesses in individual methods such as the level of robustness in the representation of biophysical reality.

Of these issues, i-vii) are discussed in Section 3.3 which details the ways that methods were combined in practice within the cases. Here we focus on the final issue where a second method was applied to increase the level of biophysical realism within the case study. This is particularly important for biophysical methods, as the application of methods with weak links to ecosystem processes increases the uncertainty in ecosystem service assessments 
(Eigenbrod et al., 2010; Lavorel et al., 2017). As such, the level and detail of the biophysical data that underlies assessments influences the ability of a method to accurately represent ecosystem service provision. Lavorel et al. (2017) differentiate between five classes of biophysical method with increasing levels of biophysical realism: i) proxy methods - which use land-use data alone as the biophysical units from which ES are provided; ii) phenomenological methods: which integrate additional understanding of the biological mechanisms which underpin ES supply (e.g. landscape configuration, species type/richness, soil quality etc.) iii) niche- and iv) trait-based models that consider distributions and abundances of species or traits and $v$ ) full process models that explicitly represent ecosystems using mathematical formulations of ecological, physical and biogeochemical processes that determine the functioning of ecosystems.

How was it addressed in the OpenNESS case studies?. Fig. 4e illustrates that whilst five cases used proxy-based methods to explore ecosystem services, none of these cases did so without an accompanying approach with a higher level of biophysical realism. Fig. 3 shows that the cases using the matrix approach based on land-use data alone (the proxy method) combined this with the integrated mapping-modelling model ESTIMAP in Slovakia and Barcelona, species distribution modelling in Warwickshire, and an STM in the Carpathians. In Romania the method was combined with photoseries analysis: a socio-cultural approach that draws on observed, geo-located species data. Furthermore, in all cases the methods were combined with participatory GIS workshops as a means of triangulating evidence and adding richness to maps based on proxy data (see Section 3.3.4).

\subsubsection{Combining methods to address different stages of the research/case study's development (decision contexts)}

Why is this important?. Within practical case studies different methods are needed at different stages of the "decision context", e.g. awareness raising, problem formulation, target setting and decision-making. This is important as the decision context determines the extent to which a combination of methods is seen as a "success" in the eyes of practitioners (see McIntosh et al., 2011; Dick et al., 2016). A number of decision contexts highlighted by the stakeholder assessments are discussed below including those related to i) spatial scale; ii) temporal scale; iii) awareness raising; iv) project evaluation and conflict resolution; v) deciding between alternatives and vi) developing policy instruments.

How was it addressed in the OpenNESS case studies?. Fig. $5 \mathrm{f}$ shows the extent to which a range of different decision contexts were considerations for method selection. In decision contexts related to spatial scale (e.g. for detailed spatial planning; providing a strategic overview or looking at a question across spatial scales), mapping approaches (integrated mapping and modelling, landuse scoring and participatory mapping) were used. Of these, land-use scoring methods were commonly selected for providing a strategic overview (71\%); whilst integrated mapping and modelling and participatory mapping were selected for detailed spatial planning (73\% and $70 \%$ respectively). Looking across spatial scales was a consideration for selecting integrated mapping modelling (80\%) and land-use scoring approaches (71\%). Of the individual methods, the spatially-explicit socio-cultural technique of photoseries analysis ranked highly against all three considerations.

For decision contexts related to temporal scale, land-use scoring, biophysical methods and integrated mapping and modelling ranked highest for assessments of the current state $(71 \%, 67 \%$, $60 \%$ respectively) whilst participatory mapping methods were the preferred methods for assessment of the future state (75\%) followed by land-use scoring (57\%) and integrative approaches (54\%). Land-use scoring ranked highest in relation to the "across temporal scales" decision context (71\%) followed by participatory mapping (45\%) and biophysical methods (44\%). However, many individual socio-economic and integrative methods were also used to address the cross-temporal consideration including narrative analysis, scenario development, deliberative valuation, photoseries and BBNs.

Awareness-raising was highlighted as a consideration in over $60 \%$ of method uses within five method classes (all except biophysical models and integrative approaches). For monetary approaches, "raising awareness of ES importance" is the only consideration addressed in $>45 \%$ of method uses. All five approaches scored highly ( $>60 \%$ ) for raising awareness of ES importance, and participatory mapping and integrated mapping-modelling was also used (>60\%) for raising awareness of trade-offs between services.

Project evaluation and conflict resolution policy contexts were both considerations for the selection of land-use scoring and integrated mapping-modelling (in $\geq 55 \%$ of method uses). Project evaluation was also a consideration in the selection of biophysical methods (56\%) whilst participatory mapping was selected to address conflict resolution (65\%).

In decision contexts where alternatives are either screened or ranked, integrated mapping-modelling, participatory mapping and land-use scoring were considered for screening (in $43-47 \%$ of method uses), whereas integrative approaches were more often considered for ranking (54\% of method uses).

In the few case studies where development of policy instruments (standards/target setting; pricing/incentives; damage compensation) was a consideration, the most commonly selected approaches were land-use scoring, integrated mapping-modelling and integrative approaches. Unsurprisingly the "pricing/incentive $s$ " decision context was the only one in which monetary methods were the method class with the greatest proportion of methods addressing the consideration (22\%).

Many of the case studies used an integrative method to draw together the results of the other methods applied in the case study. Also, many of the case-studies will have used reports (e.g. Barton et al., 2015) or presentations, meetings or workshops with end users (e.g. Kenya, Portugal): these processes are integrative methods in themselves.

\subsubsection{Additional factors driving method selection}

Above we have discussed the major drivers for combining methods, according to the stakeholders. However a number of additional factors were shown to influence method selection (e.g. when deciding between two methods that assess cultural ES values). These included: a) practical constraints (time/resources and data); b) adapting to changes in circumstance; and c) research interests of the case study teams.

Practical constraints (time/resources, data and expertise) tended to be most often mentioned with respect to certain methods that are recognised to be quicker/less data intensive than others, including participatory GIS, value transfer, cost-based methods, preference assessment, time use, expert-based mapping and photoseries analysis. In Barcelona, for example, limits on data availability and model scope led to the choice of expert-based mapping to assess soil erosion control, which was then combined with more sophisticated integrated mapping-modelling analysis of recreation and air quality using ESTIMAP. In addition, availability of expertise is a key factor both for identifying methods which link best to the actual context-oriented problem and for performing (technically) the required analyses. Within this context, adapting to changes in circumstance was often a factor influencing method choice. Factors such as changes in funding, staffing and access to expertise (e.g. visits from external experts see Section 3.3.2) led to changes methods selected for combination. In addition, research-related issues such as the interests, expertise and motivations of the research team also affected method 

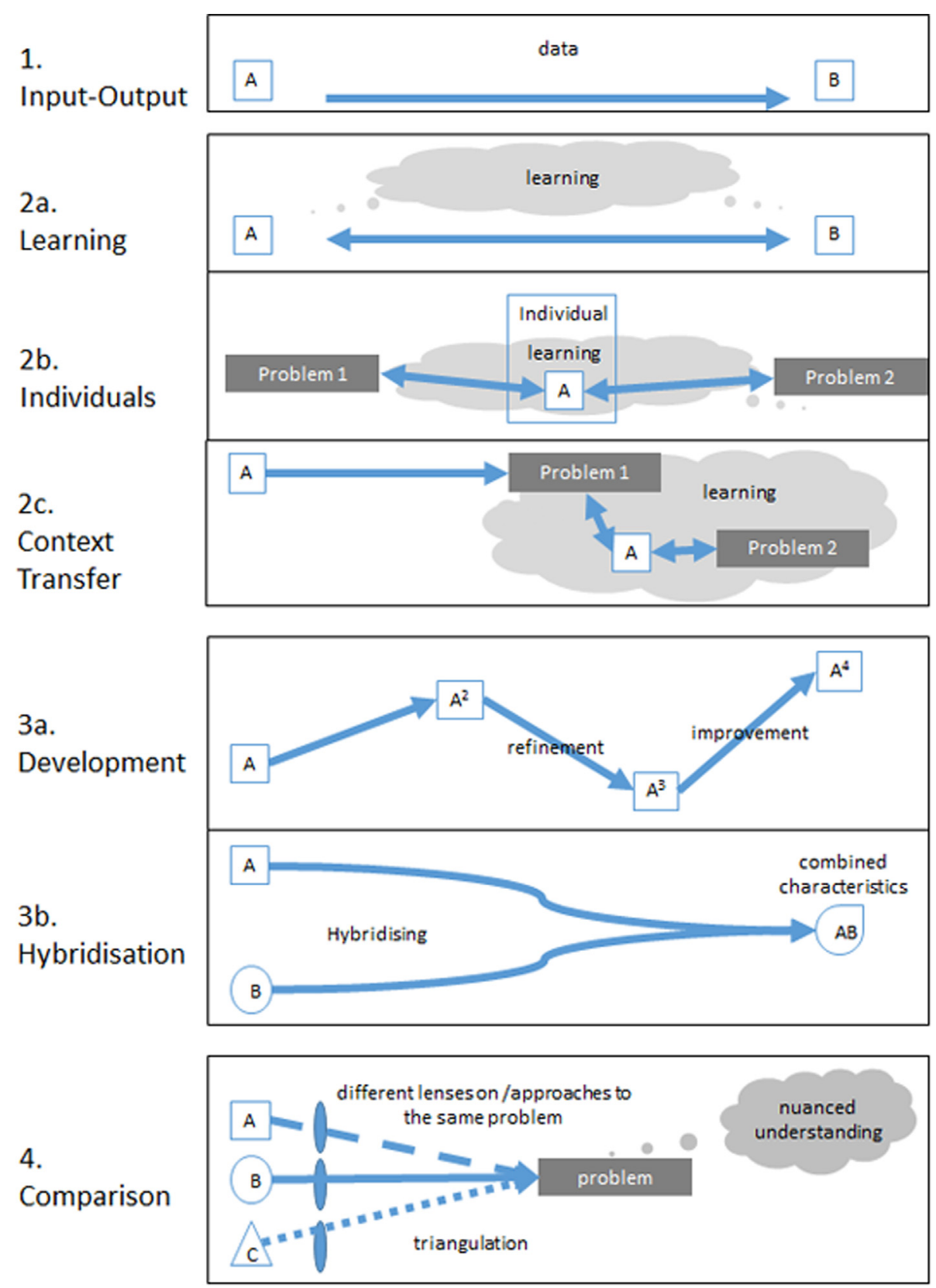

Fig. 6. Linkage between methods identified within the OpenNESS case studies.

selection (see Section 3.3.2) - this included academic curiosity in trialling a new method. Finally, the perception of methods as academically established and/or comparable with other studies also influenced method selection (see Harrison et al., 2018 for more on individual method considerations).

\subsection{How are methods combined within practical cases?}

The previous sections focussed on why different methods were combined to meet case study needs. Here we address how these methods were linked. Methods were linked in many complex and different ways, including i) input-output transfers of data between methods, but also ii) transfer of ideas, concepts and learning; iii) methods development to customise them better to the context; iv) cross-comparison of method outputs for cross- checking/validation and v) linkages of method experience across contexts.

Fig. 6 illustrates the concepts behind the types of linkage. In the sections below we draw on experiences from across all 24 case studies (Table SM4) that demonstrate these different types of linkage, with particular reference to two examples: Oslo and the Cairngorms. Fig. 7 provides a diagrammatic representation of how methods were linked within these two case studies to address their aims.

As for many of the case studies, tool selection in both cases was driven by these multiple goals related to different ES assessment issues. However, even where a specific aim was identified (e.g. Fig. $7 \mathrm{a}-02$ ), a number of different methods were combined to achieve it. The method types combined vary widely: 02 focuses almost exclusively on monetary approaches, whereas $\mathrm{C} 1 \mathrm{combines}$ aspects of biophysical, monetary and non-monetary approaches. 


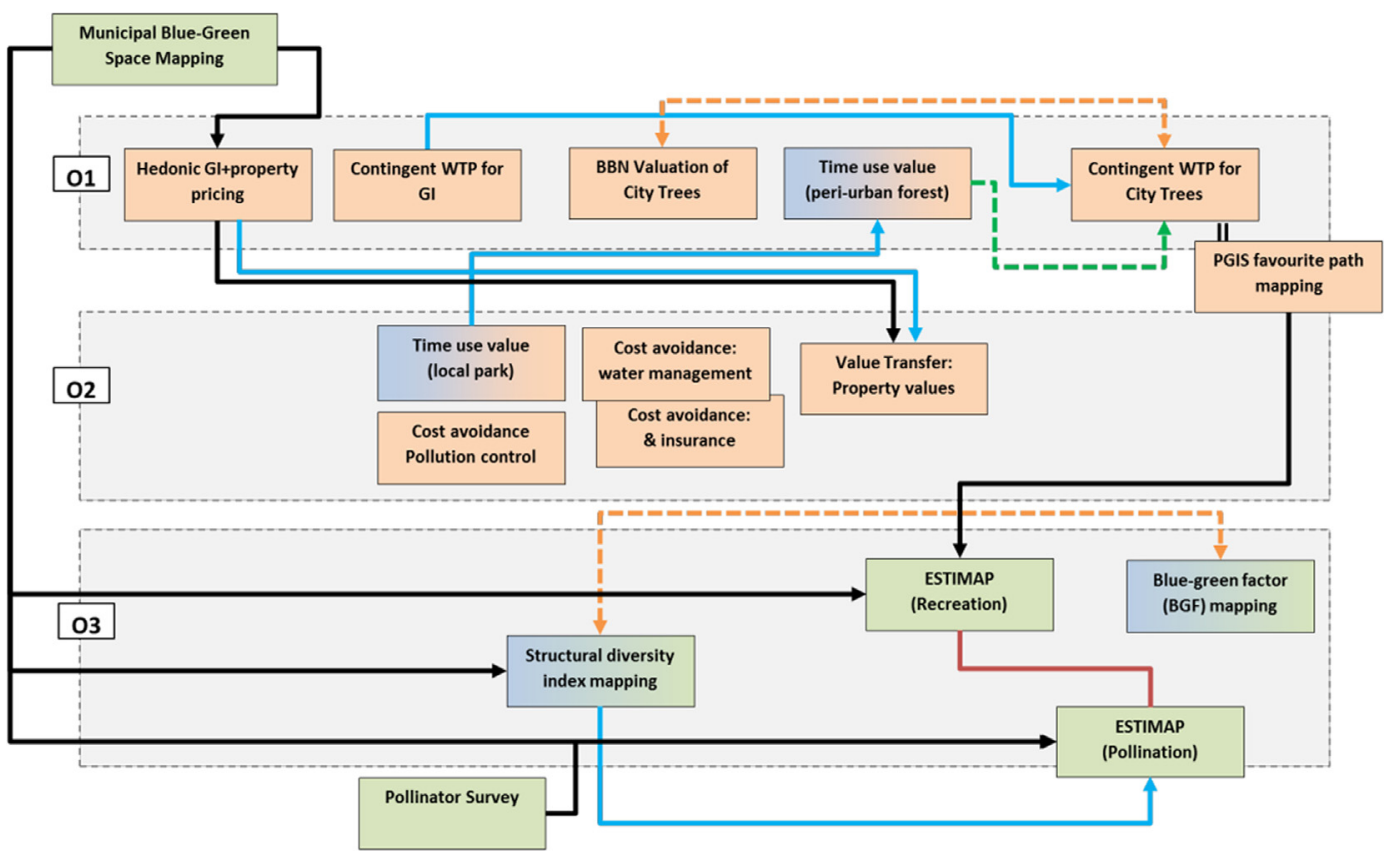

a) Oslo case study. Sub project aims: 01) to assess the monetary value of ES from Green Infrastructure at the city-scale; O2) to showcase local case study examples of the monetary value of ES to assist decision-making; and O3) to demonstrate the ability of the ESTIMAP tool

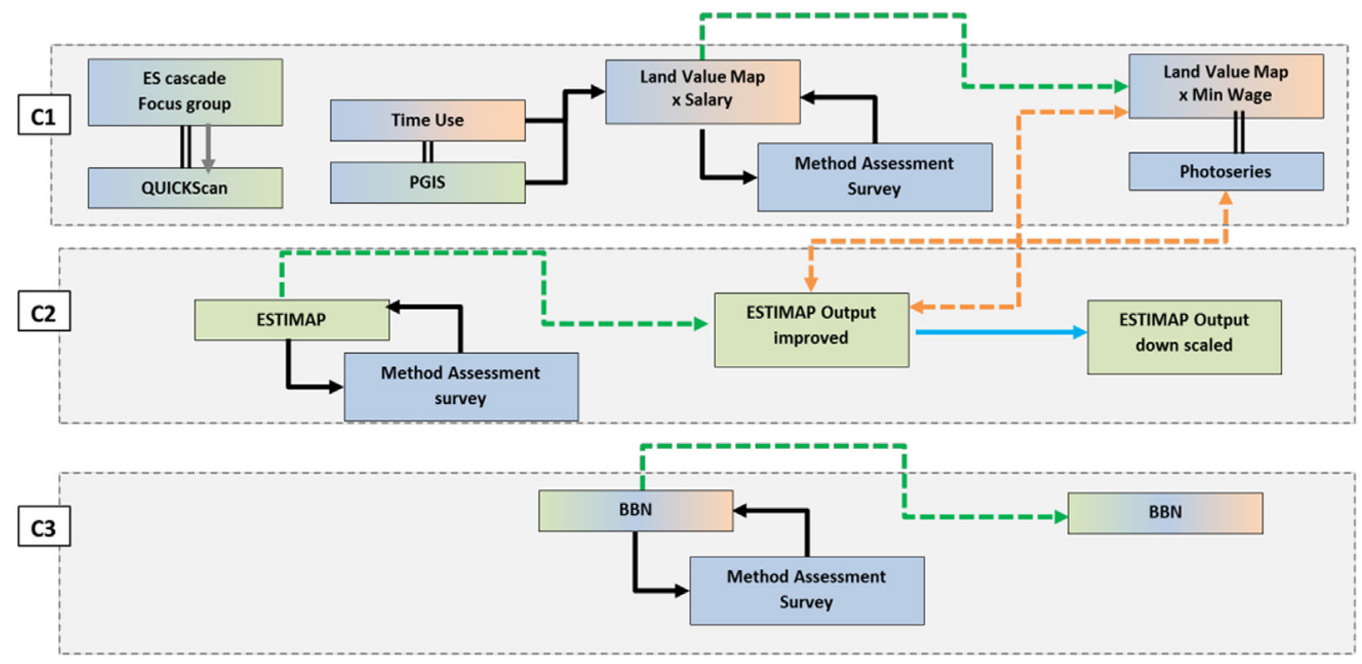

b) Cairngorms National Park case study. Sub project aims: $\mathrm{C} 1$ ) to assess the ecosystem service provision of a single land management unit (a subset of the Cairngorms National Park); C2$^{\text {) }}$ to assess the ecosystem service provision of the whole park; and (3) to assess in detail a water supply issue in a particular catchment within the study area
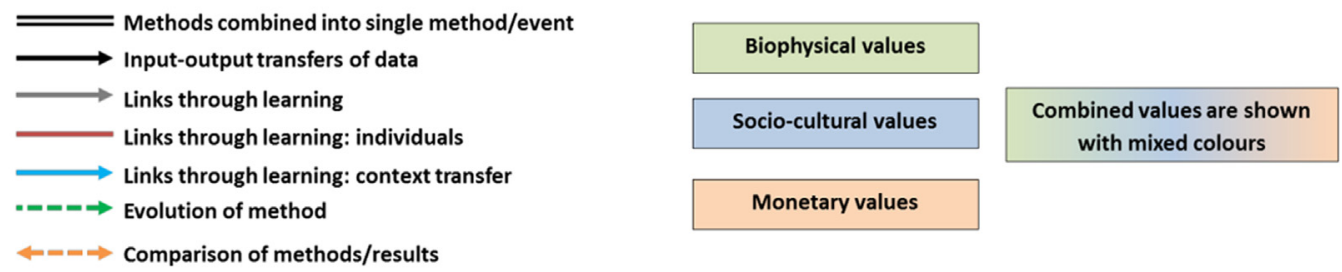

Fig. 7. a and b) Process diagrams of two example case studies Oslo, Norway and the Cairngorms National Park, Scotland.

\subsubsection{Input-output transfers of data}

Input-output transfers of data where qualitative or quantitative outputs from one method serves as the input to another were identified in 17 of the 24 cases (75\%) although the linkages them- selves took a number of different forms. These included 1) primary data collection into other methods (e.g. water availability/soil data into spatial modelling in Hungary); 2) local knowledge collection as an input to mapping/modelling (e.g. in 01 PGIS to identify 
people's favourite walking routes was an input for recreational opportunities maps using ESTIMAP); 3 ) inputs to deliberative or integrative processes (e.g. ES mapping as an input to PGIS mapping in Belgium-De Cirkel or biophysical modelling inputs to MCDA in Finland) and 4) future scenario inputs to integrated modelling approaches (France, Germany).

Inputs may also come from methods outside the case study research, e.g. from existing datasets or prior research, including value transfer from other studies. In Oslo, for example, municipal blue-green space mapping by the Agency of Urban Environment forms an input to methods in both $\mathrm{O} 1$ and $\mathrm{O} 3$ (Fig. 7). This incorporation of existing knowledge/data can be crucial and has also been shown to increase the acceptance of the ES approach by local stakeholders (e.g. Barcelona).

\subsubsection{Links through learning}

In some cases links between methods are less tangible and reflect broader learning resulting from prior experience with the method or its application (Fig. 6-2a). All 24 case studies demonstrated some kind of learning as links between methods. Some cases deliberately selected methods to encourage learning: stakeholder workshops were often used to bring all participants to a similar level of understanding of ES concepts (e.g. prior to Quickscan in C1) or specialist language and terminology (e.g. Kenya). The Belgian-De Cirkel case study, reveals two important points. Firstly, that learning isn't always positive: stakeholders almost lost interest in the ES concept following the perception of a method being inapplicable scale of local interest. Secondly, many methods, particularly deliberative approaches, are specifically designed to maximise learning through developing shared understandings between individuals. In the De-Cirkel case a simple socio-cultural technique using ES-related photographs (the "ES card game") "confirmed the relevance" of the ecosystem services to the stakeholders and enabled future ES research to proceed.

Other method combinations stimulated learning between researchers and stakeholders across academic disciplines (e.g. the MCDA approach used in Finland stimulated transdisciplinary learning by bringing scientists from different backgrounds to work together see Section 3.2.4). Others still, selected methods following prior experiences with either the cases (e.g. Barcelona prioritised non-monetary approaches due to negative stakeholder reactions to market-based methods) or with the methods (e.g. Doñana selected methods to address gaps in values captured by previous methods). Individuals, and the knowledge imbedded within them play a key role in this process (Fig. 6-2b), particularly those with methodological expertise. In the Oslo case study (01), the monetary valuation expertise of the lead researcher was a key aspect driving both method selection and method application. Many case study teams' selection of method combinations was enabled by the availability of methodological expertise (see Section 3.2.7). For example, close working relationships with the lead ESTIMAP expert in both the Oslo and Cairngorms case studies encouraged the development of the ESTIMAP methodologies in these studies, and the improved and adapted method was then transferred to other case studies as described below. Case study stakeholders and end users are also key links between methods: if the same stakeholders remain engaged with the method development process this can help retain and facilitate further learning (Saarikoski et al., 2018).

Learning also led to the transfer of methods between locations and problems leading to new method combinations in the new context (Fig. 6-2c). In the Oslo example, the time use methodology initially developed at the local scale was later applied at the municipal level (O2 $\rightarrow 01$ ) whilst the inverse was true for the hedonic pricing method $(\mathrm{O} 1 \rightarrow \mathrm{O} 2)$. In addition, contingent valuation was transferred from one topic to another at the same scale (i.e. from a focus on all green infrastructure to a focus just on city trees). Photoseries analysis was also widely transferred, being used in 11 of the case studies with learning and expertise from one case encouraging the application in another (Table SM2). Method transfer can stimulate method evolution (Section 3.3.3). The ESTIMAP methodology, for example, evolved considerably as a result of its application to different case studies. Initially intended to be applied in a standardised manner customised at a European scale (Paracchini et al., 2014), through testing across a number of OpenNESS case studies the methodology was adapted to be applicable at much finer resolutions with successful application in both national parks (e.g. Cairngorms; Costa Vicentina, Portugal) and urban areas (Oslo, Trnava, Slovakia, Helsinki, Barcelona). This was not just a downscaling of the approach but an evolution of the method from one based on standardised datasets to one that could be customised to local needs.

\subsubsection{Method evolution and development}

In 14 of the 24 cases, existing methods evolved into new and improved methods, or progressively more advanced methods were applied. In some instances this was a natural progression (Fig. 63a). For example, in Slovakia, simple land-use scoring methods (Burkhard et al., 2012) were improved by including stakeholder data from questionnaires and additional environmental datasets, to evolve the method into an advanced approach more akin to Greenframe (Kopperoinen et al., 2014). This was considered more scientifically sound and suitable for the case study's planning purposes.

In eleven of the case studies, key aspects of different methods were combined to produce hybrid methods (Fig. 6-3b). In Oslo, a web tool was developed that combined participatory mapping of favourite walking paths with a willingness-to-pay assessment of the value of city trees. In the Cairngorms example C1, a sociocultural method (time use) was hybridised with monetary valuation and PGIS approaches to produce maps of land value in terms of both time spent and monetary costs. In Patagonia, a deliberative workshop was used to enable the research team and local experts to co-design and co-produce a biophysical State and Transition Model (STM) model that could be used to evaluate forest change. In these instances, combining methodologies helps to overcome weaknesses in the individual approaches, e.g. maximising inclusion of local ecological knowledge/specialist expertise whilst producing spatial outputs/biophysical models. In another example, a case study in the French Alps combined GIS tools with a BBN model of trade-off opportunities to produce a hybrid spatial BBN. This allowed forest managers to evaluate the spatial implications and trade-offs between forest production and conservation measures to preserve biodiversity in forested habitats (Gonzalez-Redin et al., 2016).

In other examples, methods evolved in an iterative manner as a response to feedback, learning or changes in circumstance within a case study. In the Cairngorms (C1), the hybrid time use/PGIS method was improved through the use of socio-cultural methods (a stakeholder survey) to assess stakeholder concerns with the method. In response, the monetisation approach was modified from an approach based on participant salary, to one based on the minimum wage as this was thought to be a fairer reflection of value. Similarly, learning between case studies can lead to the evolution of methods. PGIS approaches trialled in Warwickshire were modified when the method was transferred to Essex, based on case study learning that suggested that, in the local context, the approach used provided better responses when focussed on cultural ecosystem services (rather than provisioning/ regulating services).

In other cases innovative new methods were developed to address aspects particularly important to the case studies. For 
example, in Hungary it was seen to be very important to include the values of future generations in ecosystem service assessments and a new "drawing competition" methodology was developed to ensure "young people get to have a voice". In the method young children were asked to contribute pictures related to their perceptions of the value of nature and their views of the future. These were included along with spatial modelling, statistical approaches and participatory mapping outputs in a final workshop that led to policy recommendations.

Finally, in some cases new methods had to be developed because existing methods were not available or contextappropriate. In Patagonia, where there was limited available data on cultural services and many of the methods proposed within OpenNESS were unsuitable because they were customised for Europe, the case study developed the photoseries approach to map and quantify cultural services.

The key point is that approaches need to evolve dynamically and respond to feedback or new opportunities that arise within the case study; and that creativity and flexibility in combining approaches increase what can be achieved.

\subsubsection{Method comparison}

Method comparison was used in 17 of the 24 cases to produce more rounded understanding of i) the ecosystem services within the case study; ii) different aspects of the case study context iii) the value of ecosystem services from different valuation lenses (monetary, socio-cultural, biophysical) and iv) the capabilities of individual methods. Triangulation of methods was a key aspect in encouraging confidence in case study results and in the identification of gaps for further research (see Section 4.1.3).

In $\mathrm{O} 2$ monetary valuation methods were used to both showcase the range of monetary tools available and highlight how they could be applied to understand different aspects of the case study context including different ES (e.g. recreation services, water and pollution management, aesthetic value). In the Cairngorms example, ESTIMAP (C2) and photoseries analysis (C1) provided a more rounded understanding of recreation ES: the first highlighting recreation potential based on spatial analysis of accessible nature whilst the other analysing geo-located photographs of locations people have actually visited and photographed nature. Comparing the two helped to identify where accessible nature is and isn't accessed, with the photographs providing additional information on the type of ES valued (e.g. aesthetic beauty, individual species or recreational events).

\section{Discussion}

We have drawn on 24 real world examples to illustrate which methods were used to meet case study priorities, why multiple methods were used, and how those methods were linked to add value to the case studies. In this discussion, we summarise the challenges and opportunities associated with combining methods, drawing on stakeholder questionnaire responses, and provide takehome messages for other practitioners.

\subsection{Challenges and opportunities in combining methods}

Many of the case studies stressed that the primary challenges and limitations were with the individual methods, but there are also a number of specific challenges related to using methods in combination.

\subsubsection{Pragmatic concerns}

Challenges faced. Practical constraints on time, cost, data availability and technical expertise (see Section 3.2.7) led to challenges for case study teams combining multiple methods: challenges that increase with the technical complexity of the methods combined. Time demands may also increase as case studies adapt and evolve due to changing understanding of the issue at hand and/or changing stakeholder interests.

Successes and opportunities. There are an increasing number of networks, tools and training opportunities to help in selecting and applying new methods, including the OPPLA hub (www.oppla.eu) and the Natural Capital Protocol Toolkit (http://naturalcapitalcoalition.org/protocol/protocol-toolkit/). The OpenNESS case studies showed how face-to-face visits from method experts can strongly influence the successful uptake of a new method (Sections 3.2.7 and 3.3.2). Echoing Jacobs et al. (2018), combining tools to ensure that all the different aspects of an ecosystem assessment are addressed does not need to be prohibitively expensive, and can provide additional benefits by enabling more cost-effective management of natural capital.

\subsubsection{Stakeholder-related}

Challenges faced. Many of case studies faced challenges in working with stakeholders, particularly i) the logistical challenges of organising stakeholder engagement activities; ii) the challenges with finding (and maintaining) a large enough sample of stakeholders - which has impacts on the perceived scientific robustness of the approach (see next section); iii) the complicating factors of the local context, such as attitudes of particular stakeholders, local rivalries and people changing roles (see also Section 3.3.2); iv) issues related to whether the results are repeatable/reproducible (see below) and v) challenges that resulted from stakeholders driving method selection and setting the decision context (see also Saarikoski et al., 2018).

Successes and opportunities. Including stakeholders in participatory processes allowed increased engagement in a number of cases (e.g. Patagonia's participatory BBN and India's participatory field work method, SM4). Furthermore it led to real-world impact in a number of cases. For example, in Slovakia the OpenNESS case study ensured that a more accurate and scientific assessment of ecosystem services was implemented, and increased the environmental awareness of stakeholders with respect to the importance of ecosystem services. This led to an improvement in the decisionmaking processes around land management which now recognise factors that encourage and discourage the use of ecosystem services. In France, the OpenNESS results will provide inputs to the next regional rural development planning exercise in the French Alps.

\subsubsection{Scientific robustness and reproducibility}

Challenges faced. Subjectivity is recognised as a fundamental aspect of all research, and scientific rigour is achieved by ensuring that methods are applied in a robust, transparent and repeatable manner. This poses challenges for a number of ES assessment tools. For participatory methods, for example, case studies cited the difficulty of selecting a representative sample of stakeholders and replicating and validating the outputs (Section 4.1.2). Challenges also arise in assessing intangible cultural ecosystem services such as aesthetic value, which reflect subjective views of the beneficiaries. Biases can arise from the use of social media-based approaches such as photoseries analysis due to limitations in the breadth of the user community (e.g. Flickr users). Scenario methodologies make assumptions based on how the future will evolve. It is important to recognise that combining multiple methods may lead to aggregation of these uncertainties, especially for methods combined in an input-output link (Section 3.3.1) or transferred across contexts (Section 3.3.4).

Successes and opportunities. Many of the case studies reported that comparing multiple methodologies (Section 3.3.4) can help to 
address problems with the robustness of individual methods through "triangulation" of results (e.g. Cairngorms, Essex, France, Loch Leven, Portugal, Warwickshire). Investigation of the similarities and differences between multiple methods can be timeconsuming, but it does add value through improving understanding of the strengths and weaknesses of the methods applied, and targeting areas for further research and method development. Nevertheless, it is important to ensure that triangulation does not create a mis-placed sense of confidence in results obtained with multiple methods.

OpenNESS research was framed as place-based and problemfocused work (post-normal science), where the research process was equally driven by local stakeholders and scientists. This required considerable flexibility and adaptability on the part of the research teams. Reproducing such a process would only be possible if the same problem was investigated in the same locality with the same stakeholders. However, this is meaningless where the aim is to solve real life problems. Rigour can be enhanced by encouraging iteration and feedback with relevant stakeholders and external experts, and by building on the findings of previous published studies. In OpenNESS, stakeholder-led case study advisory boards provided this "validity check" function, by discussing the results and raising any concerns that required further investigation of modifications to methodology.

The use of multiple methods also poses challenges where there is a need for comparable, standardised approaches at national or international levels, such as the EU MAES process (Mapping and Assessment of Ecosystem Services, Maes et al., 2013) and the UN SEEA EEA (System of Environmental and Economic Accounts Experimental Ecosystem Accounting, UNSD (2014)). Where possible, comparability should be facilitated by linking methodology to existing standards. Tools such as translation keys to link the ES terminology used in case studies to standard ecosystem service lists (e.g. Common International Classification of Ecosystem Services: CICES), the use of transferable methods (such as InVEST and ESTIMAP) and protocols for a common blueprint for ES studies (Seppelt et al., 2012) may assist with this.

\subsubsection{Combining disparate methods}

Challenges faced. We have illustrated the benefits of combining a wide variety of ecosystem service tools in different ways, to tackle complex real-world problems that require interdisciplinary approaches to encompass a range of values, services and stakeholders. But this is not to say that every tool can be combined with every other tool without overcoming significant differences in methodology.

Practical challenges are associated in combining methods that differ in the services addressed, types of values captured, level of biophysical realism, measurement and output units, spatial units and scale of the analysis. Comparing biophysical and sociocultural research outputs was a challenge in many of the cases (e.g. Hungary, Slovakia, Sierra Nevada) as not all outputs "fit together". For example, geo-located social media photographs and questionnaire responses both bring useful insights but it is challenging to combine the two into a single integrated result (Patagonia). These kinds of challenge are particularly pertinent for input-output (Section 3.3.1) linkages and for cases where comparison for validation (Section 3.3.4) is considered. Linking methods with very different levels of scientific complexity can also inhibit transfer of learning (Section 3.3.2). In the Finland case, for example, it was clear that BBNs can become very complicated: it takes a lot of effort to fill in probability tables and this can lead to stakeholders losing interest.

In addition to methodological challenges there are also epistemological and ontological challenges (Vatn, 2009). Biophysical, monetary and socio-economic methodologies stem from very different disciplinary backgrounds with different epistemological stances on what constitutes robust knowledge, and ontological stances on whether robust knowledge is possible (Section 4.1.3). It can therefore be very challenging for researchers from different backgrounds to work together, and thus to combine methods from these different disciplinary origins.

Successes and opportunities. Despite these significant challenges, $63 \%$ of the OpenNESS research teams stated that the combinations of methods used within their case studies had met their needs, whilst the remaining $37 \%$ replied with a qualified affirmative (reflecting the challenges discussed in this section). The OpenNESS case studies highlight the importance of flexibility and creativity when it comes to practical ES assessments, and all research teams stress the importance of embedding stakeholder engagement within the core of the research process. Many methodological challenges can be overcome with sufficient time, resources and expertise (e.g. Dick et al., 2016; García-Llorente et al., 2015). GIS skills are particularly useful in this regard (Oslo). Ontological/ epistemological concerns can also be addressed. Interdisciplinary approaches do take time to find common ground, but research teams reported that they ultimately fostered a collaborative atmosphere between different scientific disciplines and also between researchers and non-researchers, as it was clear that the scientists were also learning from the process (e.g. Hungary, BelgiumStevoort, Finland; Saarikoski et al., 2018). Whilst differences in ontology/epistemology should not be overlooked, practical deliberative approaches such as workshops, meetings, presentations and informal discussions with stakeholders that incorporate an awareness of the strengths and limitations of different methods can help to integrate disparate methods into a coherent output even in the absence of shared units or a common spatial framework (Essex, Warwickshire, Hungary).

\subsubsection{Scale}

Challenges faced. A number of case studies reported challenges related to scale, spatial extent and spatial resolution. Working at large scales (e.g. large regions, national, international) leads to challenges for validation, particularly of social science methodologies, and increases the challenge of convening representative stakeholder groups (Hungary, Essex, Brazil). Both fine and broad scales can pose challenges for obtaining datasets at the right spatial resolution (Barcelona). Some methods are more appropriate for certain scales (e.g. the Cairngorms case found ESTIMAP to be appropriate for the national park scale, but too coarse when zoomed in) and method scale can limit utility for particular decision needs (e.g. see Section 3.2.6). Spatial extent may need to vary to cover different ES. In the Portuguese case, the default case study boundary needed to be extended to cover the spatial extent of marine ecosystems and pollination services relevant to the study.

Successes and opportunities. Whilst data availability can be a key constraint, in many cases spatial challenges can be resolved with the application of resources and expertise, particularly GIS skills which facilitate the transfer of datasets between scales (Oslo). There are many cases where methods were successfully combined at the same scale (e.g. Loch Leven, Warwickshire) or adapted to transfer across scales (e.g. Barcelona, Helsinki, Oslo; Section 3.3.2). Methods can be combined to make up for deficiencies in spatial resolution. For example, the Cairngorms case study combined local surveys that were impossible to conduct at the national park level with integrated mapping-modelling that was suitable only at a broader scale. With sufficient time, methods can be nested and cross-scale approaches can be taken (Patagonia, Sierra Nevada; Martín-López et al., 2017). Cross-scale approaches can be very important for integrated valuation as values can vary with spatial resolution, because of the level of aggregation and the spatial 
context. For example, the individual value of a street tree is different to the value of a similar tree in a park or forest (Oslo). Even where spatial challenges persist, e.g. for methods linked by input-output data (Section 3.3.1) and direct-overlay comparisons (Section 3.3.4), they can contribute to case-based learning (Section 3.3.2) by allowing stakeholders a more nuanced understanding of an issue.

\subsection{Take-home messages}

Some of the details identified above will reflect the particular features of the OpenNESS project, but the key messages are transferable to any ecosystem services assessment. In this section we summarise key messages for practitioners concerning the selection and combination of methods.

\subsubsection{Why use combinations of methods in ecosystem service assessments?}

There are a wide variety of ecosystem service assessment tools available, and an increasing number of approaches to help users decide which tool to use (Harrison et al., 2018; OPPLA). However, this paper demonstrates that assessments can be strengthened by combining a number of different methods. This can yield the following benefits.

- Individual tools are unlikely to address all the needs of a given context, but a range of approaches can be used to assess different aspects of ES, such as different types of green infrastructure, different groups of services, different geographic scales or timescales, and different types of value (e.g. biophysical, sociocultural and monetary);

- Certain tools, especially deliberative tools such as workshops, can be used to transfer knowledge, concepts and ideas amongst researchers, local experts, specialists and stakeholders, which can facilitate uptake of ecosystem service concepts and thus enable the implementation of additional tools such as biophysical models;

- Valuable learning and opportunities for model improvement can be gained by transferring methods across projects at different scales or locations.

- Combining methodologies into hybrid approaches helps to overcome weaknesses in the individual approaches, e.g. including local ecological knowledge or specialist expertise in biophysical models;

- Hybrid approaches or evolutionary development of existing tools can increase analytical capability or reduce uncertainty, e.g. combining the trade-off analysis of a BBN with the spatial analysis and visualisation of a GIS mapping tool to create a spatial BBN;

- Drawing flexibly on a range of methods can allow new methods to be deployed in response to changes in the focus of the project;

- Applying multiple methods can allow cross-comparison, thus providing an indication of the level of uncertainty in the assessment and potentially highlighting biases or weaknesses in the approach;

\subsubsection{What methods should be combined?}

There is no one-size-fits-all solution to ecosystem services assessment, and it is beyond the scope of this paper to provide definitive guidance on which tools to combine, as this will depend on the case study context. However, it is clear that researchers should plan to build in a range of techniques to cover different aspects of the issue in question. Based on the experience of the OpenNESS case studies, a general recommendation would be:
Step 1) Set-up. Identify a representative stakeholder group; convene an advisory board to ensure robustness; and assess user needs. This will require socio-cultural techniques (surveys, workshops, interviews, etc.) and there are a number of tools that can be used within these to enrich the information content of the process (e.g. the ES card game). Be prepared to iterate throughout the process.

Step 2) Scoping. Use quick, simple methods to build an understanding of the issue, e.g. land-use scoring; participatory mapping. These low-cost and informal methods can also provide an opportunity to start building mutual understanding and a shared language between stakeholders and researchers from different disciplines.

Step 3) Evaluation. Use a combination of monetary, sociocultural, mapping and modelling methods to meet the needs of the case, ensuring that the chosen approaches reflect the range of different values that stakeholders hold (see Jacobs et al., 2018). The level of biophysical realism that can be applied will depend on the needs of the case study, the time and budget, and available expertise. Visits from method experts can be invaluable. Applying multiple methods to address the same problem can help with assessing uncertainty, enhancing understanding and building confidence in the results. Periodic review by the advisory board can help to ensure robustness and identify potential method improvements. A flexible and creative approach may allow methods to be improved and hybrid or novel methods to emerge in response to new information or stakeholder feedback.

Step 4) Integration. Use an integrating approach to draw the different assessments together. This need not be complex or numerical: it could be a deliberative workshop with the relevant stakeholders drawing together the outputs from the different methods.

\section{Conclusion}

This paper has demonstrated the range and variety of methods applied in ecosystem service assessment in 24 case studies across a wide range of contexts. It has highlighted the ways in which methods can be combined, and identified the range of considerations addressed when selecting methods. Combining different methods can greatly strengthen ES assessments, allowing them to address the full range of relevant ES and value types, engaging different stakeholder groups, highlighting areas of uncertainty, building a deeper understanding of the socio-ecological system, and facilitating method development and learning. However there are a number of challenges to be addressed, including practical constraints on time, resources and expertise, and the difficulties of interdisciplinary working. Successful application of combined methods will require a good understanding of the strengths and weaknesses of individual methods, and maintain a flexible and dynamic approach that can respond to opportunities and constraints as they arise.

Whilst the complexity of socio-ecological systems and the competing demands for nature's goods and services present major challenges for ecosystem management, the case studies presented here demonstrate how ecosystem service assessment methods can be combined in innovative and creative ways to create customised solutions that address practical user needs. By sharing and learning from the experiences of stakeholders, practitioners and researchers from different disciplines (e.g. via the OPPLA hub), we can ensure that these innovative approaches diffuse quickly and enhance our options for sustainably managing the services our ecosystems provide. 


\section{Acknowledgements}

This research was funded by the European Union EU FP7 project OpenNESS (Grant agreement no. 308428). The OpenNESS project is solely responsible for the content of this publication. It does not represent the opinion of the European Union, nor is the European Union responsible for any use that might be made of information appearing herein.

\section{Appendix A. Supplementary data}

Supplementary data associated with this article can be found, in the online version, at https://doi.org/10.1016/j.ecoser.2017.10.014.

\section{References}

Bagstad, K.J., Semmens, D.J., Waage, S., Winthrop, R., 2013. A comparative assessment of decision-support tools for ecosystem services quantification and valuation. Ecosyst. Serv. 5, E27-E39.

Bateman, I.J., Harwood, A.R., Abson, D.J., Andrews, B., Crowe, A., Dugdale, S., Fezzi, C., Foden, J., Hadley, D., Haines-Young, R., Hulme, M., Kontoleon, A., Munday, P. Pascual, U., Paterson, J., Perino, G., Sen, A., Siriwardena, G., Termansen, M., 2014. Economic analysis for the UK national ecosystem assessment: synthesis and scenario valuation of changes in ecosystem services. Environ. Resour. Econ. 57, $273-297$.

Barton, Stange, Blumentrath, Traaholt, 2015. Economic valuation of ecosystem services for policy a pilot study on green infrastructure in Oslo", NINA report 1114. Available online at http://www.openness-project.eu/sites/default/ files/NINA\%20Report\%201114\%20\%20\%20Ecosystem\%20service\%20valuation\% 200slo\%20pilot_final_web.pdf.

Barton, D.N., Kelemen, E., Dick, J., Martin-Lopez, B., Gómez-Baggethun, E., Jacobs, S., Hendriks, C.M.A., Termansen, M., García- Llorente, M., Primmer, E., Dunford, R., Harrison, P.A., Turkelboom, F., Saarikoski, H., van Dijk, J., Rusch, G.M., Palomo, I., Yli-Pelkonen, V.J., Carvalho, L., Baró, F., Langemeyer, J., van der Wal, J.T., Mederly, P., Priess, J.A., Luque, S., Berry, P., Santos, R., Odee, D., Pastur, G.M., García Blanco, G., Saarela, S-R.-R., Silaghi, D., Pataki, G., Masi, F., Vădineanu, A., Mukhopadhyay, R., Lapola, D.M., 2018. (Dis) integrated valuation - Assessing the information gaps in ecosystem service appraisals for governance support. Ecosyst. Serv. 29, 529-541.

Burkhard, B., Kroll, F., Nedkov, S., Müller, F., 2012. Mapping Ecosystem Service supply, demand and budgets. Ecological Indicators 21, 17-29.

Dick, J., Verweij, P., Carmen, E., Rodela, R., Andrews, C., 2016. Testing the ecosystem service cascade framework and QUICKScan software tool in the context of landuse planning in Glenlivet Estate Scotland. Int. J. Biodiv. Sci. Ecosyst. Serv. Manage. Open Access.

Eigenbrod, F., Anderson, B., Armsworth, P., Heinemeyer, A., Gillings, S., Roy, D., Thomas, C., Gaston, K., 2010. Representation of ecosystem services by tiered conservation strategies. Conservation Letters. https://doi.org/10.1111/j.1755263X.2010.00102.x.

García-Llorente, M., Iniesta-Arandia, I., Willaarts, B., Harrison, P.A., Berry, P., Bayo, M.M., Castro, A.J., Montes, C., Martín-López, B., 2015. Biophysical and sociocultural factors underlying spatial tradeoffs of ecosystem services in semiarid watersheds. Ecol. Soc. 20 (3), 39. https://doi.org/10.5751/ES-07785-200339.

Gómez-Baggethun,E., Barton, D., Berry, P., Dunford, R.W., Harrison, P.A., (2016) "Concepts and methods in ecosystem services valuation". In: Potschin, M., et al. Routledge Handbook of Ecosystem Services, Routledge ISBN-10: 1138025089.

Gonzalez-Redin J, Luque, S., Poggio, L., Smith, R., Gimona, A., 2016. Spatial Bayesian belief networks as a planning decision tool for mapping ecosystem services trade-offs on forested landscapes. Environmental Research Volume 144, Part B, Pages 15-26 Special Issue: The Provision of Ecosystem Services in Response to Global Change doi:10.1016/j.envres.2015.11.009.

Grêt-Regamey, A., Sirén, E., Brunner, S.H., Weibel, B., 2017. Review of decision support tools to operationalize the ecosystem services concept. Ecosyst. Serv. (in press)

Haines-Young and Potschin, 2010. 2010 The links between biodiversity, ecosystem services and human well-being. In: Raffaelli, D., Frid, C. (Eds.), Ecosystem Ecology: A New Synthesis. Cambridge University Press, Cambridge, pp. 110139.

Harrison, Paula A., Dunford, Rob, Barton, David N., Kelemen, Eszter, Martín-López, Berta, Norton, Lisa, Termansen, Mette, Saarikoski, Heli, Hendriks, Kees, GómezBaggethun, Erik, Czúcz, Bálint, García-Llorente, Marina, Howard, David, Jacobs, Sander, Karlsen, Martin, Kopperoinen, Leena, Madsen, Anders, Rusch, Graciela, van Eupen, Michiel, Verweij, Peter, Smith, Ron, Tuomasjukka, Diana, Zulian, Grazia, 2018. Selecting methods for ecosystem service assessment: a decision tree approach. Ecosyst. Serv. 29, 481-498.

Hirons, M., Comberti, C., Dunford, R., 2016. Valuing cultural ecosystem services. Annu. Rev. Environ. Resour. 41, 545-574.

IPBES, 2015. Preliminary guide regarding diverse conceptualization of multiple values of nature and its benefits, including biodiversity and ecosystem functions and services (deliverable 3 (d)). Intergovernmental Sci. Policy Platform Biodivers. Ecosyst. Serv.
Jacobs, S., Martín-López, B., Barton, D., Dunford, R., Harrison, P., Kelemen, E. Saarikoski, H., Termansen, M., García-Llorente, M., Gómez-Baggethun, E., Kopperoinen, L., Luque, S., Palomo, I., Priess, J., Rusch, G., Tenerelli, P., Turkelboom, F., Demeyer, R., Hauck, J., Keune, H., Smith, R., 2018. The means determine the end - Pursuing integrated valuation in practice. Ecosyst. Serv. 29, 515-528. https://doi.org/10.1016/j.ecoser.2017.07.011.

Kopperoinen, L., Itkonen, P., Niemelä, J., 2014. Using expert knowledge in combining green infrastructure and ecosystem services in land use planning: an insight into a new place-based methodology. Landscape Ecology. https://doi.org/ 10.1007/s10980-014-0014-2.

Lavorel, S., Bayer, A., Bondeau, A., Lautenbach, S., Ruiz-Frau, A., Schulp, N., Seppelt, R., Verburg, P., Teeffelen, A.V., Vannier, C., Arneth, A., Cramer, W., Marba, N., 2017. Pathways to bridge the biophysical realism gap in ecosystem services mapping approaches. Indic, Ecol. 10.1016/j.ecolind.2016.11.015.

Maes, J., Teller, A., Erhard, M., Liquete, C., Braat, L., Berry, P., Egoh, B., Puydarrieux, P. Fiorina, F., Santos, F., Paracchini, M.L., Keune, H., Wittmer, H., Hauck, J., Fiala, I., Verburg, P., Condé, S., Schägner, J.P., San Miguel, J., Estreguil, C., Ostermann, O. Barredo, J.I., Pereira, H.M., Stott, A., Laporte, V., Meiner, A., Olah, B., Royo Gelabert, E., Spyropoulou, R., Petersen, J.E., Maguire, C., Zal, N., Achilleos, E. Rubin, A., Ledoux, L., Brown, C., Raes, C., Jacobs, S., Vandewalle, M., Connor, D. and Bidoglio, G., 2013. Mapping and Assessment of Ecosystems and their Services. An analytical framework for ecosystem assessments under action 5 of the EU biodiversity strategy to 2020. European Union.

Maes, J., Liquete, C., Teller, A., Erhard, M., Paracchini, M.L., Barredo, J.I., Grizzetti, B. Cardoso, A., et al., 2016. An indicator framework for assessing ecosystem services in support of the EU Biodiversity Strategy to 2020. Ecosyst. Serv. 17, 14-23.

Martín-López, B., Palomo, I., García-Llorente, M., Iniesta-Arandia, I., Castro, A., García Del Amo, D., Gómez-Baggethun, E., Montes, C., 2017. Delineating boundaries of social-ecological systems for landscape planning: A comprehensive spatial approach. Land Use Policy 66, 90-104.

Martínez Pastur, G., Peri, P.L., Lencinas, M.V., García Llorente, M., Martín López, B. 2016. Spatial patterns of cultural ecosystem services provision in Southern Patagonia. Landscape Ecol. 31, 383-399.

Martinez-Harms, M.J., Bryan, B.A., Balvanera, P., Law, E.A., Rhodes, J.R., Possingham, H.P., Wilson, K.A., 2015. Making decisions for managing ecosystem services. Biol. Conserv. 184, 229-238.

McIntosh, B.S., Ascough, J.C., Twery, M., Chew, J., Elmahdi, A., Haase, D., Harou, J.J., Hepting, D., Cuddy, S., Jakeman, A.J., Chen, S., Kassahun, A., Lautenbach, S., Matthews, K., Merritt, W., Quinn, N.W.T., Rodriguez-Roda, I., Sieber, S., Stavenga, M., Sulis, A., Ticehurst, J., Volk, M., Wrobel, M., van Delden, H., El-Sawah, S. Rizzoli, A., Voinov, A., 2011. Environmental decision support systems (EDSS) development - Challenges and best practices. Environ. Model. Softw. 26. https:// doi.org/10.1016/j.envsoft.2011.09.009.

Paracchini, M.L., Zulian, G., Kopperoinen, L., Maes, J., Schägner, J.P., Termansen, M. Zandersen, M., Perez-Soba, M., Scholefield, P.A., Bidoglio, G., 2014. Mapping cultural ecosystem services: a framework to assess the potential for outdoor recreation across the EU. Ecol. Indic. 45, 371-385. https://doi.org/10.1016/j. ecolind.2014.04.018.

Ruckelshaus, M., McKenzie, E., Tallis, H., Guerry, A., Daily, G., Kareiva, P., Polasky, S., Ricketts, T., Bhagabati, N., Wood, S.A., Bernhardt, J., 2015. Notes from the field: lessons learned from using ecosystem service approaches to inform real-world decisions. Ecol. Econ. 115, 11-21.

Saarikoski, Heli, Primmer, Eeva, Saarela, Sanna-Riikka, Antunes, Paula, Aszalós, Réka, Baró, Francesc, Berry, Pam, Blanco, Gemma Garcia, Goméz-Baggethun, Erik, Carvalho, Laurence, Dick, Jan, Dunford, Robert, Hanzu, Mihail, Harrison, Paula, Izakovicova, Zita, Kertész, Miklós, Kopperoinen, Leena, Köhler, Berit Langemeyer, Johannes, Lapola, David, Liquete, Camino, Luque, Sandra, Mederly, Peter, Niemela, Jari, Palomo, Ignacio, Pastur, Guillermo Martinez, Peri, Pablo, Preda, Elena, Priess, Joerg, Santos, Rui, Schleyer, Christian, Turkelboom, Francis, Vadineanu, Angheluta, Verheyden, Wim, Vikström, Suvi, Young, Juliette, 2018. Institutional challenges in putting ecosystem service knowledge in practice. Ecosyst. Serv. 29, 579-598.

Seppelt, R., Fath, B., Burkhard, B., Fisher, J.L., Grêt-regamey, A., Lautenbach, S., Pert, P., Hotes, S., Spangenberg, J., Verburg, P.H., Van Oudenhoven, A.P.E.E., 2012. Form follows function? Proposing a blueprint for ecosystem service assessments based on reviews and case studies. Ecol. Indic. 21, 145-154. https://doi.org/10.1016/j.ecolind.2011.09.003.

TEEB, 2010. The Economics of Ecosystems and biodiversity: mainstreaming the economics of nature: a synthesis of the approach, conclusions and recommendations of TEEB. TEEB ocotber 2010.

Tenerelli, P., Demšar, U., Luque, S., 2016. Crowdsourcing indicators for cultural ecosystem services: A geographically weighted approach for mountain landscapes. Ecol Indic 64, 237-248. https://doi.org/10.1016/j.ecolind.2015.12.042.

UN, Ec, FAO, Imf, OECD, Bank, W., 2014. System of Environmental-Economic Accounting 2012 - experimental ecosystem accounting. United Nations, New York.

UNSD, 2014, 'System of Environmental-Economic Accounting 2012, experimental ecosystem accounting', United Nations Statistics Division, Washington, DC, USA http://unstats.un.org/unsd/envaccounting/seeaRev/eea_final_en.pdf accessed $13 / 1 / 2017$.

Vatn, A., 2009. An institutional analysis of methods for environmental appraisal Ecol. Econ. 68, 2207-2215.

Wijnja, van Uden, Delbaere, 2016. Ecosystem services in operation: case studies. European Commission FP7.

Zulian, G., Polce, C., Maes, J., 2014. ESTIMAP: a GIS-based model to map ecosystem services in the European union. Ann. di Bot. 4, 1-7. https://doi.org/10.4462 annbotrm-11807. 